\title{
Lifetime incremental cost-utility ratios for minimally invasive surgery for degenerative lumbar spondylolisthesis relative to failed medical management compared with total hip and knee arthroplasty for osteoarthritis
}

\author{
Eric J. Crawford, MD \\ Robert A. Ravinsky, MDCM, MPH \\ Peter C. Coyte, PhD \\ Y. Raja Rampersaud, MD
}

Presented at the 17th Annual Scientific Conference of the Canadian Spine Society, Feb. 22-25, 2017, Montréal, Que.; the SpineFEST, University of Toronto, June 12, 2017, Toronto, Ont.; and the Canadian Orthopaedic Association, Annual Meeting, June 20-23, Victoria, B.C.

\section{Accepted May 27, 2020}

\section{Correspondence to:}

Y.R. Rampersaud

Division of Orthopaedic Surgery

Toronto Western Hospital

University Health Network

First Floor, East Wing, Rm 1E449

399 Bathurst St

Toronto ON M5T 2S8

raja.rampersaud@uhn.ca

DOI: $10.1503 /$ cjs.015719
Background: The objective of this study was to compare the cost-effectiveness of minimally invasive surgery (MIS) for patients with degenerative lumbar spondylolisthesis (DLS) relative to failed medical management with the cost-effectiveness of hip and knee arthroplasty for matched cohorts of patients with osteoarthritis.

Methods: A cohort of patients with DLS undergoing MIS procedures with decompression alone or decompression and instrumented fusion between 2008 and 2014 was matched to cohorts of patients with hip osteoarthritis $(\mathrm{OA})$ and knee OA undergoing total joint replacement. Incremental cost-utility ratios (ICURs) were calculated from the perspective of the Ontario Ministry of Health, using prospectively collected Short Form-6 Dimension utility data. Costs and quality-adjusted life years (QALYs) were discounted at $3 \%$ and sensitivity analyses were performed.

Results: Sixty-six patients met the inclusion criteria for the DLS cohort $(n=35$ for decompression alone), with a minimum follow-up time of 1 year (mean $1.7 \mathrm{yr}$ ). The mean age of patients in the DLS cohort was 64.76 years, and 45 patients $(68.2 \%)$ were female. For each cohort, utility scores improved from baseline to follow-up and the magnitude of the gain did not differ by group. Lifetime ICURs comparing surgical with nonsurgical care were Can\$7946/QALY, Can\$7104/QALY and Can\$5098/QALY for the DLS, knee OA and hip OA cohorts, respectively. Subgroup analysis yielded an increased ICUR for the patients with DLS who underwent decompression and fusion (Can\$9870/QALY) compared with that for the patients with DLS who underwent decompression alone (Can\$5045/QALY). The rank order of the ICURs by group did not change with deterministic or probabilistic sensitivity analyses.

Conclusion: Lifetime ICURs for MIS procedures for DLS are similar to those for total joint replacement. Future research should adopt a societal perspective and potentially capture further economic benefits of MIS procedures.

Contexte : L'objectif de cette étude était de comparer le rapport coût-efficacité de la chirurgie minimalement effractive (CME) chez les patients atteints de spondylolisthésis lombaire dégénératif (SLD) en lien avec un échec de la prise en charge médicale à celui de l'arthroplastie de la hanche et du genou pour des cohortes assorties de patients atteints d'arthrose.

Méthodes : Une cohorte de patients atteints de SLD soumis à une CME avec décompression seule ou décompression avec arthrodèse entre 2008 et 2014 a été assortie à des cohortes de patients soumis à une arthroplastie totale pour arthrose de la hanche et du genou. Les rapports coût-utilité différentiels (RCUD) ont été calculés du point de vue du ministère de la Santé de l'Ontario à l'aide des données d'utilité du questionnaire Short Form-6 Dimension recueillies de manière prospective. Les coûts et les années de vie ajustées en fonction de la qualité (AVAQ) ont été actualisés à un taux de $3 \%$ et des analyses de sensibilité ont été effectuées.

Résultats : Soixante-six patients répondaient aux critères d'inclusion pour la cohorte SLD ( $n=35$, décompression seule), avec un suivi d'une durée minimale de 1 an (moyenne 1,7 an). L'âge moyen des gens de la cohorte SLD était de 64,76 ans, et 45 patients $(68,2 \%)$ étaient de sexe féminin. Pour chaque cohorte, les scores d'utilité se sont améliorés entre les valeurs de départ et les valeurs de suivi et l'ampleur du gain n'a pas 
différé entre les groupes. Les RCUD pour la vie entière entre les soins chirurgicaux et non chirurgicaux ont été 7946\$CA/QALY, 7104\$CA/QALY et 5098 \$CA/QALY pour les cohortes SLD, arthrose du genou et de la hanche, respectivement. L'analyse de sous-groupes a généré un RCUD accru pour les patients atteints de SLD qui ont subi la décompression avec arthrodèse (9870 \$CA/QALY) comparativement à la décompression seule (5045 \$CA/QALY). Le classement des RCUD par groupe n'a pas changé en fonction des analyses de sensibilité déterministes ou probabilistes.

Conclusion : Les RCUD pour la vie entière associés à la CME dans les cas de SLD sont similaires à ceux de l'arthroplastie totale. Les recherches futures devraient adopter une perspective sociétale et refléter davantage les bienfaits économiques de la CME.

I $\mathrm{n}$ recent years there has been an increasing demand for hip and knee replacement surgery; the same is true of surgical procedures for degenerative conditions of the spine. Moreover, it is projected that these demands will continue to increase for the foreseeable future. ${ }^{1,2}$ These trends may be attributable to both an aging population and increased societal emphasis on quality of life, as well as the development of increasingly refined minimally invasive surgical (MIS) techniques. Degenerative lumbar spondylolisthesis (DLS) is a common indication for spinal surgery. ${ }^{3}$ It is a well-studied and common clinical entity, noted to peak between the fifth and eighth decades of life. ${ }^{4-6}$ As a comparator, hip and knee replacement, or total joint replacement (TJR), has also been extensively studied and has been refined over the last 5 decades. In fact, primary TJR has been shown to be among the most cost-effective operations in existence, and it has been shown to substantially improve patient health-related quality of life (HRQoL).,

It has been previously demonstrated by Rampersaud and colleagues that patients undergoing open surgical treatment for focal lumbar spinal stenosis (FLSS) can expect similar improvements in HRQoL from baseline to 5 -year postoperative follow-up, when compared with an age- and sex-matched cohort of patients undergoing total hip and knee arthroplasty. ${ }^{7}$ With regard to comparative cost-utility ratios between these groups, Rampersaud and colleagues have also previously demonstrated comparable incremental cost-utility ratios (ICURs) for patients undergoing open management of FLSS when compared with patients undergoing total hip and knee arthroplasty at a median of 5 years of follow-up. ${ }^{8}$

In this FLSS cohort, only a subgroup had stenosis secondary to DLS. Additionally, this previous FLSS cohort underwent open surgical approaches by 2 different surgeons and there was a lack consistency in this treatment arm, as $72 \%$ of patients underwent decompression alone while the remaining patients underwent decompression and instrumented fusion, with differing surgical techniques and exposure-related morbidity.?

Symptomatic DLS is an established indication for lumbar decompression and fusion. Glassman and colleagues studied patients with various lumbar spine conditions managed with lumbar fusion surgery and found that the DLS subgroup experienced the greatest improvement in function, as measured by the Oswestry Disability Index (ODI) at a 2-year follow-up. ${ }^{3}$ Additionally, the SPORT trials showed sustainable improvement in outcome of DLS treated surgically at 4-year follow-up. ${ }^{12,13}$

Compared with open surgery, MIS spine surgery may be advantageous when considering factors such as patient morbidity, as well as the length of hospital stay and the overall cost associated with surgery and perioperative care. It has been demonstrated that compared with open posterior lumbar fusion, patients undergoing MIS procedures tend to lose less blood, are discharged from hospital earlier, ambulate earlier and experience fewer medical and surgical adverse events. ${ }^{14-20}$

It is our hypothesis that for DLS, MIS decompression and fusion or, in appropriate cases, decompression alone can reliably produce improvements in HRQoL and ICURs similar to those produced with TJR procedures, which may be considered gold standard procedures with respect to both patient outcomes and cost-effectiveness.

\section{Methods}

\section{Study design}

A single-centre observational cohort study was undertaken to compare the relative cost-utility of modern surgical procedures for common degenerative conditions of the spine, hip and knee, relative to failed medical management. Specifically, MIS procedures for DLS of the spine were compared with TJR for hip and knee osteoarthritis (OA). This study employed a similar methodology to that described by Rampersaud and colleagues. ${ }^{8,21}$ In this paper we focused on a homogeneous population of spine patients with DLS, who underwent the same MIS procedures and thus were more homogeneous in terms of surgical morbidity and hospital length of stay (LOS). Additionally, a contemporaneous cohort of patients undergoing TJR for hip and knee replacements with improved clinical pathways (i.e., shorter LOS and reduced cost) was being compared. Furthermore, both deterministic sensitivity analyses and probabilistic sensitivity analyses are presented, in keeping with the current standards in health economic research. ${ }^{22}$ This analysis was performed with prospectively collected patient outcomes 
and retrospectively compiled patient costs. The study received approval from the University Health Network Research Ethics Board.

\section{Incremental cost-utility analysis}

ICURs were used to compare the additional cost per additional benefit for patients associated with surgical management relative to failed medical management for 3 common degenerative musculoskeletal conditions. An ICUR involves the measurement of costs, in standard monetary units and utility, reported in quality-adjusted life years (QALYs). The use of standard units, such as dollars and QALYs, allows for the comparison of ICURs for treatments across multiple conditions. We compared ICURs for the surgical management of DLS, hip OA and knee OA, relative to failed medical management. ICURs for each condition were calculated by determining the difference in costs between surgical and medical management and dividing this by the difference in QALYs obtained with each treatment strategy. Given that both the surgical and medical treatment groups consisted of patients for whom medical management had failed, the baseline utility was assumed to be equal for the 2 groups. Additionally, we assumed that QALYs in the medical management group did not change from baseline, because there was no change in treatment strategy.,13 Therefore, QALYs gained by the surgical group represented the estimated difference in QALYs between the surgical and medical management groups. Similar assumptions were made for costs, and the costs related to surgery (hospital, rehabilitation and possible revision surgery costs) were assumed to represent the estimated difference in costs between the 2 treatments. ${ }^{8,13}$

The primary outcome was lifetime ICURs (costs per QALY) for surgical relative to failed medical management for DLS and OA of the hip and knee. Costs were reported in 2016 Canadian dollars, from the perspective of the provincial health insurance system, the single health insurance payer in the province of Ontario. Life years remaining at the time of surgery were calculated for each patient on the basis of age- and sex-specific life tables for Ontario for 2009-2011, as reported by Statistics Canada. ${ }^{23}$ To acknowledge the concept of time preference, which refers to the increased value that society places on immediate costs and benefits compared with those accrued in the future, both costs and QALYs were discounted at an annual rate of $3 \% .{ }^{24}$ To account for variation in the discount rate and its effect on the ICUR, annual discount rates of 0 and 5 were used in the sensitivity analysis.

\section{Patient population}

Patients with DLS who underwent MIS decompression with or without fusion between January 2008 and
December 2014 were obtained from a search of the surgical database of a fellowship-trained spine surgeon at a tertiary academic centre. All patients had radiographic evidence of 1- or 2-level DLS, with no associated coronal plane spinal deformity, resulting in associated spinal stenosis and symptoms consistent with neurogenic claudication (leg-dominant pain with activity, relieved with postural change) reported on history, and had at least 6 months of failed medical management. To be included, patients also had to have prospectively collected Short Form-6 Dimension (SF-6D) utility scores available at baseline and either 1 or 2 years after surgery. Patients were excluded if they underwent multilevel surgery greater than 2 levels, underwent open surgical procedures, had prior spine surgery at the symptomatic or adjacent levels or had radiographically demonstrated multilevel deformity in the coronal or sagittal planes. Cases of isthmic spondylolisthesis were also excluded.

Consecutive surgical cases were reviewed against the above selection criteria. Each patient meeting the criteria was independently matched with a patient with hip OA and a patient with knee OA, who underwent total hip arthroplasty (THA) and total knee arthroplasty (TKA), respectively, on a 1:1:1 basis. Patients were matched with respect to sex, age (within $2 \mathrm{yr}$ ) and date of surgery (within 6 mo).

Inclusion criteria for patients undergoing TJR were mechanical joint pain of the affected joint with OA demonstrated on radiographs and at least 6 months of failed medical management. Patients with secondary OA (posttraumatic) or an inflammatory arthropathy were excluded. Additionally, patients were excluded if they had had previous surgery on their symptomatic joint, with the exception of knee arthroscopy.

\section{Surgery}

For patients with DLS for whom medical management had failed, who elected to proceed with surgery, MIS decompression-alone procedures were offered to patients with neurogenic claudication, no or minimal mechanical back pain, anatomy favourable to a facet-sparing (i.e., undercutting) decompression, grade 1 (i.e., up to $25 \%$ ) spondylolisthesis on radiographs, and no evidence of dynamic instability (an increase in 4-5 mm of spondylolisthesis demonstrated on flexion-extension or standing compared with supine radiographs). Decompression-alone procedures were performed from a unilateral approach with a tubular retractor (Tubular Retractor System, METRx, Medtronic) and involved a midline-sparing bilateral decompression. Patients not meeting the above criteria underwent MIS decompression and instrumented fusion procedures, which entailed a unilateral transforaminal interbody fusion (TLIF) using a cage and autologous bone graft, MIS decompression and percutaneous pedicle screw fixation. 
Patients with hip OA for whom medical management failed and who decided to proceed with surgery underwent uncemented THA, performed from a lateral (Harding) approach. Cemented TKA using a medial para-patellar approach was performed for patients with knee OA for whom medical management failed and who elected to proceed with surgical management.

\section{Treatment effectiveness}

Patients completed either the 12-item or 36-item Short Form Survey before surgery and at 1 or 2 years after surgery; their scores were converted to SF-6D utility scores. ${ }^{25}$ Given that patients had outcome data at either 1 or 2 years postoperatively, or both, each patient's longest follow-up was selected as their postoperative outcome. To calculate QALYs in an unbiased manner, we assumed that utility gains occurred over a 1-year period for all patients. This assumption was made on the basis of data from this study and the literature that suggest there is no statistical difference in 1- or 2-year outcome data for the surgical populations reported on in this study. ${ }^{9,13}$ Lifetime QALYs were determined by the area under the curve for the graph of utility gained by life years remaining.

\section{Treatment costs}

Costs were considered from the perspective of the provincial health insurance system and included hospital, rehabilitation and revision surgery costs. All costs are reported in Canadian dollars and were inflated to 2016 values on the basis of consumer price indexing data from the Bank of Canada. ${ }^{26}$

Surgery costs included micro-costed perioperative and hospital admissions costs for each patient. These costs were obtained from the financial department at the Toronto Western Hospital and included both direct and indirect (overhead) costs. The cost components that we included were operating room costs (surgical implants and prostheses, central processing department, anesthesia, postanesthesia care unit), nursing (postoperative care unit, ward and intensive care unit), physiotherapy, respiratory therapy, patient support workers, pharmacy, medical imaging, laboratories and food. Physician fees were not included to allow for the comparison of previously published results. ${ }^{8,21}$

Costs of inpatient and home-based rehabilitation programs were based on averages reported in a randomized controlled trial comparing these 2 rehabilitation strategies in patients undergoing THA and TKA. ${ }^{27}$ An assumption was made that all patients undergoing TJR participated in either an inpatient or home-based postoperative rehabilitation program. On the basis of TJR rehabilitation data reported by the Ministry of Health, it was assumed that the discharge rate to inpatient rehabilitation facilities was $20 \% .{ }^{28}$ Available rates reported over the study period by the Ministry of Health ranged from $8.2 \%$ to $25.2 \% .^{29}$

The cost of revision surgery was based on the cohort averages reported in the present study. Revision surgery costs were calculated in the same manner as described for the index procedure, and again they included the same inpatient rehabilitation rate. Additionally, for patients requiring revision surgery, typical medical imaging ordered before surgery was included. Specifically, this included orthogonal radiographs of the affected limb for patients undergoing TJR and a contrast enhanced magnetic resonance image (MRI) of the lumbar spine. Radiograph costs were based on those reported in the Ministry of Health Schedule of Benefits Fees - Physician Services and Ministry of Health Schedule of Facility Fees..$^{30,31}$ MRI costs were obtained from the Ontario Case Costing Initiative and based on ambulatory (outpatient) data from the Toronto Western Hospital between 2010 and 2011 and included both direct and indirect costs. ${ }^{32}$

\section{Sensitivity analysis}

Deterministic and probabilistic sensitivity analyses were performed. Costs of primary and revision surgery, revision rates, percentage of inpatient rehabilitation (for TJR groups), utility and discount rates were varied for the analysis. Primary and revision surgery costs were varied between mean cohort costs $\pm 25 \%$. Because we estimated lifetime ICURs, long-term revision rates for TJR and MIS lumbar decompression and fusion procedures were taken from the literature. For both THA and TKA, a revision rate of $\pm 25 \%$ of $12 \%$ was used, on the basis of a systematic review of revision rates in arthroplasty with an approximate average follow-up period of 9 years. ${ }^{33}$ Similarly, for DLS decompression alone and decompression and fusion procedures, revision rates of $\pm 25 \%$ of $28.0 \%$ and $\pm 25 \%$ of $17.1 \%$ were used, respectively, in keeping with values published in a large cohort study of more than 24000 patients with an average follow-up of 11 years. ${ }^{34}$ Lifetime QALYs gained were varied by $95 \%$ confidence interval (CI) limits by reported cohort means. The percentage of inpatient rehabilitation admission for TJR cohorts was varied from $0 \%$ to $40 \%$. Costs and QALYs were discounted at rates of $0 \%, 3 \%$ and $5 \%$, to determine their effect on the ICUR. The deterministic analyses are reported as average and best- and worst-case scenarios in addition to a graphical representation of each variable's influence on the ICUR.

A probabilistic sensitivity analysis (PSA) was performed using uniform distributions for the ranges described above. For each cohort a Monte Carlo simulation with 1000 iterations was performed, with random sampling from the distributions. Results are reported as ICURs with associated 95\% CIs. To conduct these analyses, a decision analysis was performed for each cohort to compare the costs and utility 
changes between surgical and nonsurgical care. TreeAge Pro 2016 software was used to perform these analyses. Cohort-specific decision analysis trees are displayed in the 3 figures in Appendix 1 (available at canjsurg.ca/015719-a1). All other statistics reported were generated with Stata 14.2.

\section{Results}

Sixty-six patients with DLS undergoing MIS procedures met the inclusion criteria and had complete outcome data. All of these patients had a minimum of 1 year of follow-up data, with an average follow-up of 1.7 years. With respect to the types of surgery performed, 35 patients underwent decompression alone and 31 underwent decompression and fusion procedures. Each patient was successfully matched with a patient with hip $\mathrm{OA}$ and another with knee OA, who underwent THA and TKA, respectively.

Patient baseline characteristics are displayed in Table 1. Patient body mass index (BMI) differed between the groups, with patients who underwent knee OA having a higher BMI than patients who underwent hip OA (mean difference 3.4, $p=0.002$, analysis of variance [ANOVA]). Additionally, the American Society of Anesthesiologists (ASA) physical status classification score differed between the groups ( $p=0.03$, Kruskal-Wallis test). Patients with DLS had a higher median ASA score (2.5) than those with with hip OA (2) and knee OA (2). Because neither BMI nor ASA score was associated with outcomes (utility change or total costs), the described group differences were not adjusted for in the subsequent analyses.

Average total per patient hospital costs (direct and indirect) were \$12233 for THA, \$12 099 for TKA, $\$ 7156$ for decompression alone and $\$ 19934$ for decompression and fusion. A further breakdown of costs, including revision and rehabilitation data, is displayed in Table 2, in addition to average patient length of stay by group. Across all cohorts, utility scores changed significantly ( $p<0.001$, paired $t$ tests) from baseline to followup with mean utility gains of 0.161 (SD 0.143) for THA,
0.113 (SD 0.132) for TKA, 0.118 (SD 0.136) for DLS decompression alone and 0.137 (SD 0.134) for DLS decompression and fusion. The magnitude of utility change did not differ by surgical cohort $(p=0.12$, ANOVA, for all patients with DLS; $p=0.36$, ANOVA, for DLS decompression and matched TJR cohorts; $p=$ 0.33, ANOVA, for DLS decompression and fusion and matched TJR cohorts). Subgroup analysis demonstrated that patients with DLS undergoing fusion procedures reported lower utility values at baseline $(p<0.001$, ANOVA) and follow-up ( $p<0.001$, ANOVA) than matched patients who underwent THA and TKA, although, as previously stated, they experienced equivocal utility gains from baseline to follow-up compared with their arthroplasty counterparts. Specific subgroup utility scores and group differences are displayed in Table 3. QALYs gained over the lifetime were modelled using a $3 \%$ discount rate, which yielded gains of 2.470 for THA, 1.784 for TKA, 1.658 for DLS decompression alone and 2.276 for DLS decompression and fusion.

\section{Sensitivity analysis}

Lifetime ICURs, calculated with a discount rate of $3 \%$ applied to both costs and QALYs, were \$5098/QALY for THA, \$7104/QALY for TKA, \$5045/QALY for DLS decompression alone and \$9870/QALY for DLS decompression and fusion. Results by matched subgroups are displayed in Table 4, in addition to the results of the sensitivity analyses. Best- and worst-case scenarios were calculated as described in the Methods. The largest range was observed for the ICUR for the DLS decompression and fusion cohort (best-case scenario \$3563/QALY; worst-case scenario \$25258/QALY). Further results of the deterministic sensitivity analysis are presented in Figure 1, Figure 2, Figure 3 and Figure 4, which display each factor's influence on the ICUR, by surgical cohort. In all cohorts, the ICUR was sensitive to changes in the surgical costs, QALYs, the discount rate applied and inpatient rehabilitation rates (for TJR cohorts) and less

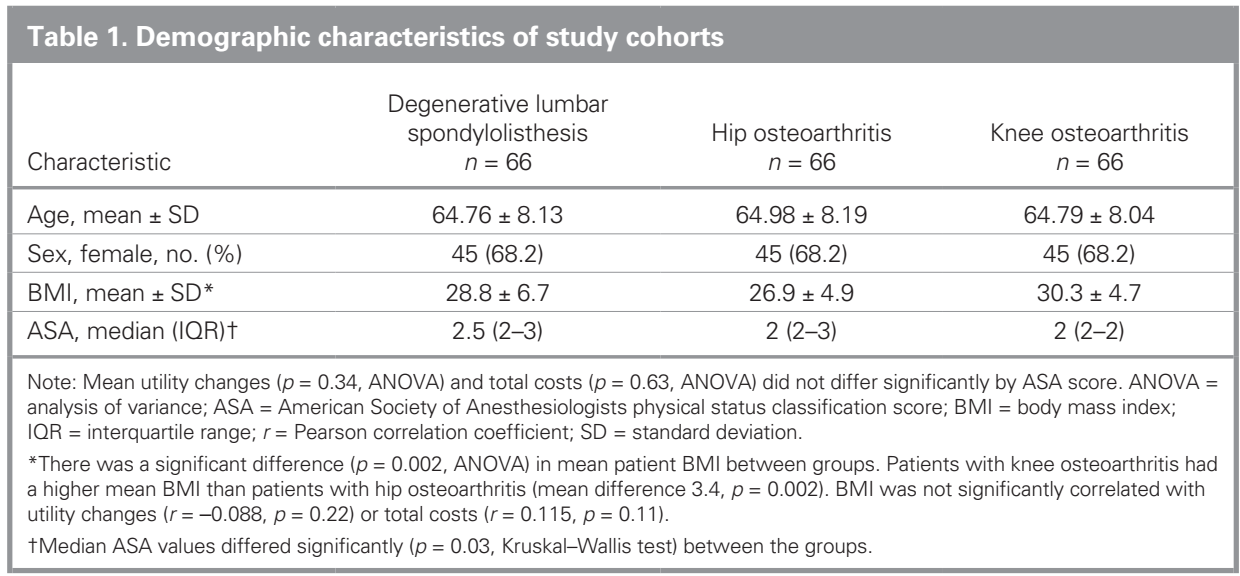




\begin{tabular}{|c|c|c|c|c|c|c|c|c|c|}
\hline \multirow[b]{2}{*}{ Measure } & \multicolumn{3}{|c|}{ All patients } & \multicolumn{3}{|c|}{$\begin{array}{c}\text { Patients with DLS who underwent } \\
\text { decompression alone, and the matched patients } \\
\text { with hip or knee OA }\end{array}$} & \multicolumn{3}{|c|}{$\begin{array}{c}\text { Patients with DLS who underwent } \\
\text { decompression with fusion, and the matched } \\
\text { patients with hip or knee OA }\end{array}$} \\
\hline & $\begin{array}{c}\text { MIS } \\
\text { decompression } \\
\text { with or without } \\
\text { fusion for DLS } \\
\quad n=66\end{array}$ & $\begin{array}{l}\text { Primary THA } \\
\text { for hip OA } \\
n=66\end{array}$ & $\begin{array}{c}\text { Primary TKA } \\
\text { for knee OA } \\
\quad n=66\end{array}$ & $\begin{array}{l}\text { MIS } \\
\text { decompression } \\
\text { for DLS } \\
n=35\end{array}$ & $\begin{array}{l}\text { Primary THA } \\
\text { for hip OA } \\
n=35\end{array}$ & $\begin{array}{l}\text { Primary TKA } \\
\text { for knee OA } \\
\quad n=35\end{array}$ & $\begin{array}{c}\text { MIS } \\
\text { decompres- } \\
\text { sion and fusion } \\
\text { for DLS } \\
n=31\end{array}$ & $\begin{array}{c}\text { Primary THA } \\
\text { for hip OA } \\
n=31\end{array}$ & $\begin{array}{c}\text { Primary TKA } \\
\text { for knee OA } \\
\quad n=31\end{array}$ \\
\hline $\begin{array}{l}\text { Average cohort } \\
\text { lifetime ICUR, } \\
\text { point estimate, } \\
\text { \$/QALY }\end{array}$ & 7946 & 5098 & 7104 & 5045 & 5824 & 8206 & 9870 & 4338 & 5886 \\
\hline $\begin{array}{l}\text { Lifetime ICUR, } \\
\text { \$/QALY } \\
(95 \mathrm{Cl} \%)^{*}\end{array}$ & $\begin{array}{c}8177 \\
(8077-8277)\end{array}$ & $\begin{array}{c}5196 \\
(5136-5256)\end{array}$ & $\begin{array}{c}7242 \\
(7144-7340)\end{array}$ & $\begin{array}{c}5371 \\
(5280-5463)\end{array}$ & $\begin{array}{c}6216 \\
(6115-6318)\end{array}$ & $\begin{array}{c}8838 \\
(8664-9013)\end{array}$ & $\begin{array}{l}10472 \\
(10304-10 \\
641)\end{array}$ & $\begin{array}{c}4477 \\
(4417-4537)\end{array}$ & $\begin{array}{c}6223 \\
(6118-6329)\end{array}$ \\
\hline $\begin{array}{l}\text { Worst-case } \\
\text { scenario lifetime } \\
\text { ICUR, \$/QALY† }\end{array}$ & 17062 & 10396 & 15850 & 12666 & 14260 & 23297 & 25258 & 9692 & 15464 \\
\hline $\begin{array}{l}\text { Best-case } \\
\text { scenario lifetime } \\
\text { ICUR, \$/QALY }\end{array}$ & 3204 & 2056 & 2724 & 1959 & 2183 & 2874 & 3563 & 1619 & 2068 \\
\hline $\begin{array}{l}\text { Note: } \mathrm{Cl}=\text { confiden } \\
\text { quality-adjusted life } \\
{ }^{*} \text { Based on a probab } \\
\text { tWorst-case scena } \\
\text { undergoing revision }\end{array}$ & $\begin{array}{l}\text { e interval; DLS = de } \\
\text { ear; THA = total hip } \\
\text { istic sensitivity anal } \\
\text { ICUR was determ } \\
\text { surgery, } 40 \% \text { inpatie }\end{array}$ & $\begin{array}{l}\text { enerative lumbar } \\
\text { arthroplasty; TKA } \\
\text { sis, cost and QAL } \\
\text { led using the me } \\
\text { tt rehabilitation fo }\end{array}$ & $\begin{array}{l}\text { pondylolisthesis } \\
\text { total knee arthr } \\
\text { s discounted at } \\
\text { primary surger } \\
\text { THA and TKA, a }\end{array}$ & $\begin{array}{l}\text { CUR }=\text { incremental } \\
\text { lasty. } \\
\text { annual rate of } 3 \% \text {. } \\
\text { ost plus } 25 \% \text {, the r } \\
\text { the lower limit of } t\end{array}$ & $\begin{array}{l}\text { ost-ulity ratios; } N \\
\text { ean revision surg } \\
95 \% \mathrm{Cl} \text { for } \mathrm{QAL}\end{array}$ & $\begin{array}{l}S=\text { minimally in } \\
\text { y cost plus } 25 \% \\
\text { 's gained and a }\end{array}$ & $\begin{array}{l}\text { asive surgery; } \mathrm{OA}= \\
\text { the upper limit of } \mathrm{t} \\
\% \text { discount rate. }\end{array}$ & steoarthritis; Q & ients \\
\hline $\begin{array}{l}\ddagger \text { \# Best-case scenari } \\
\text { undergoing revision }\end{array}$ & $\begin{array}{l}\text { CUR was determin } \\
\text { argery, } 0 \% \text { inpatier }\end{array}$ & $\begin{array}{l}d \text { using the mear } \\
\text { rehabilitation for }\end{array}$ & $\begin{array}{l}\text { orimary surgery } \\
\mathrm{HA} \text { and TKA, a }\end{array}$ & $\begin{array}{l}\text { minus } 25 \% \text {, the } \\
\text { e upper limit of th }\end{array}$ & $\begin{array}{l}\text { ean revision sur } \\
95 \% \mathrm{Cl} \text { for } \mathrm{QAL}\end{array}$ & $\begin{array}{l}\text { cost minus } 2 \\
\text { gained and a }\end{array}$ & $\begin{array}{l}\text {, the lower limit o } \\
\text { discount rate. }\end{array}$ & he proportion & patients \\
\hline
\end{tabular}

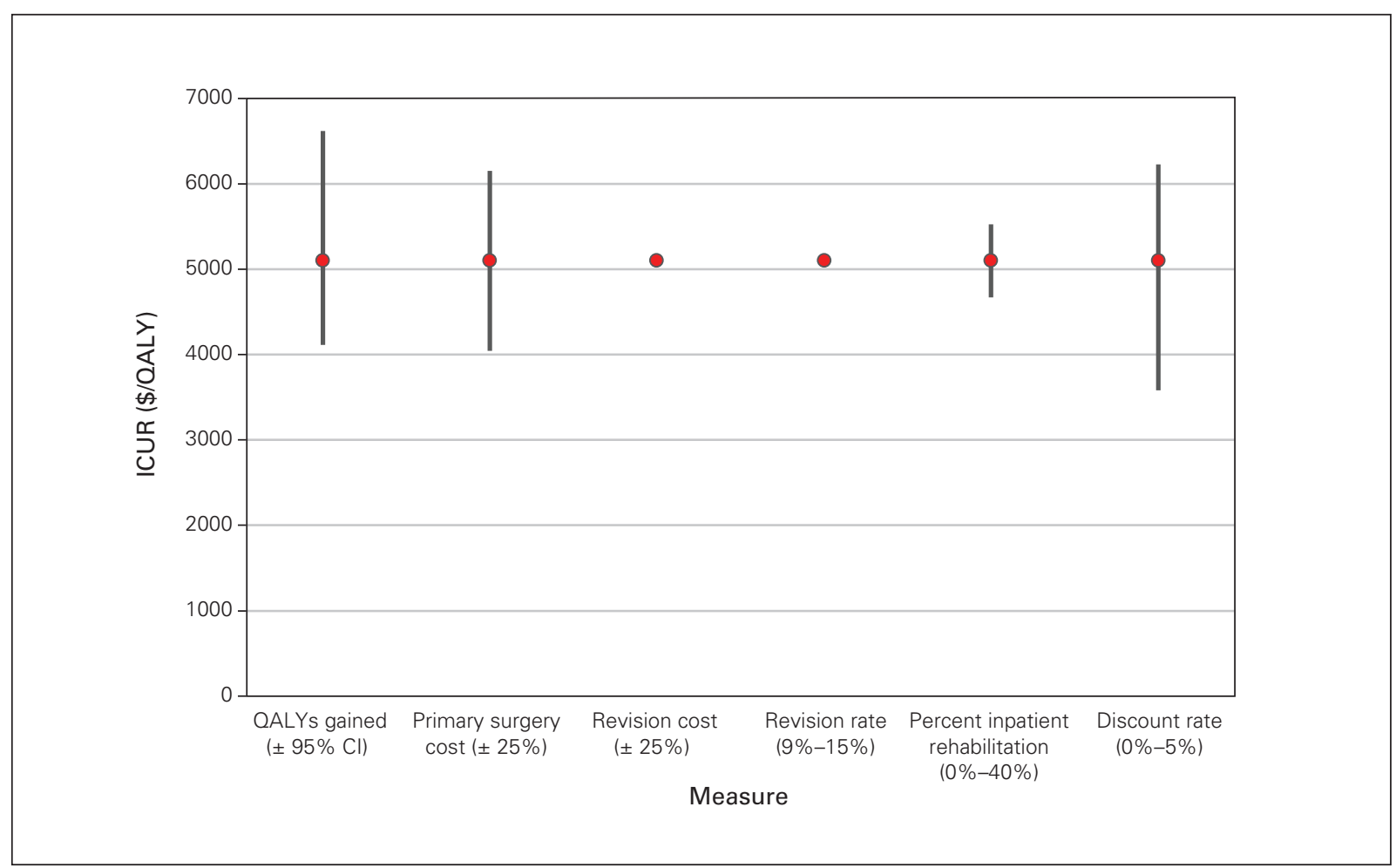

Fig. 1. Deterministic sensitivity analysis for the 66 patients who underwent total hip arthroplasty. $\mathrm{Cl}=\mathrm{confidence}$ interval; ICUR = incremental cost-utility ratio; $\mathrm{QALY}=$ quality-adjusted life year.

sensitive to revision costs and revision rates. In fact, for the TJR cohorts reported, the ICUR was nearly insensitive to variation in the revision rates and costs.
Results of the PSA by cohort and subgroup are also displayed in Table 4. ICURs generated by the PSA were similar to our cohort estimates, indicating that our 


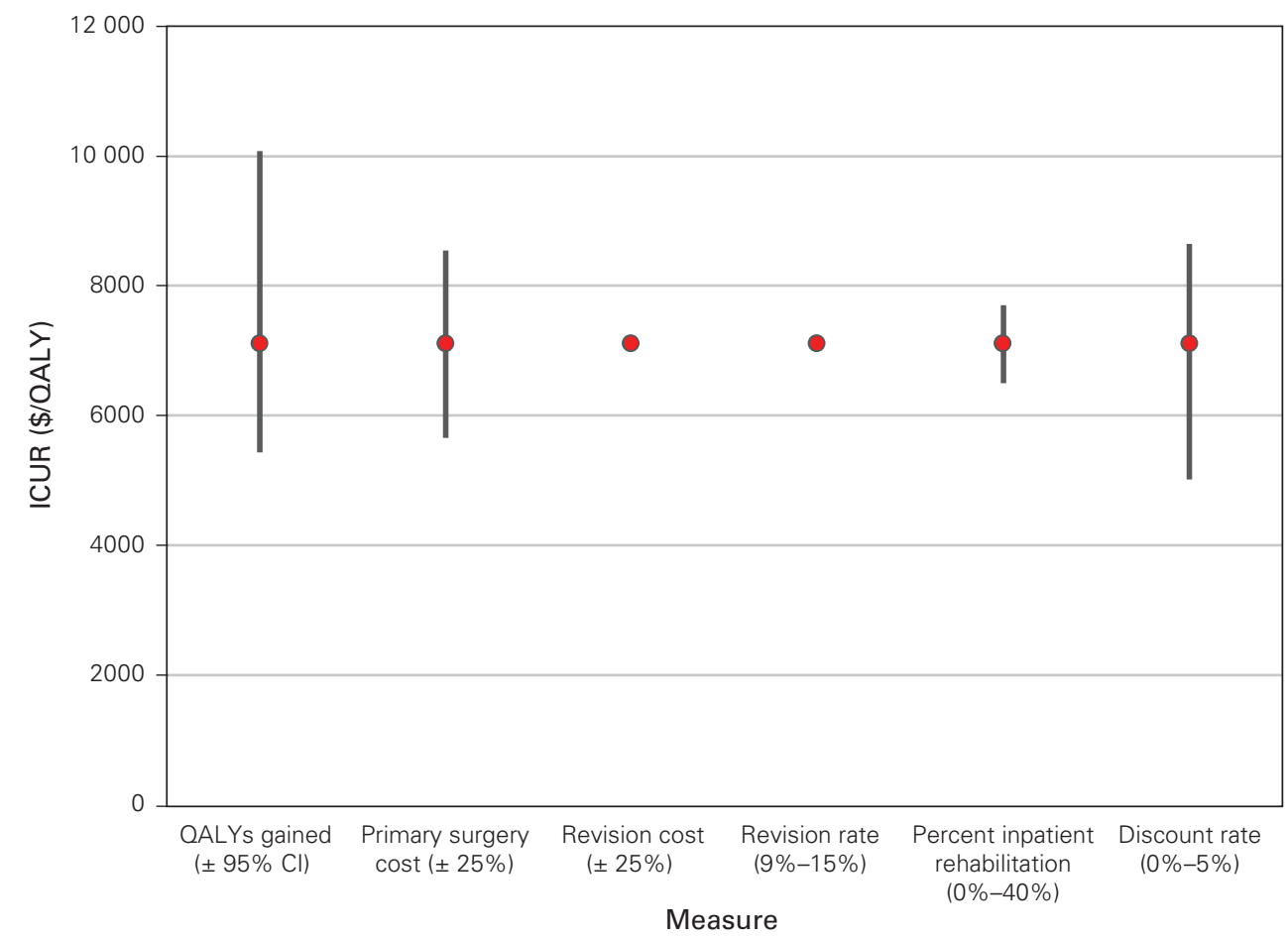

Fig. 2. Deterministic sensitivity analysis for the 66 patients who underwent total knee arthroplasty. $\mathrm{Cl}=$ confidence interval; ICUR = incremental cost-utility ratio; $\mathrm{QALY}=$ quality-adjusted life year.

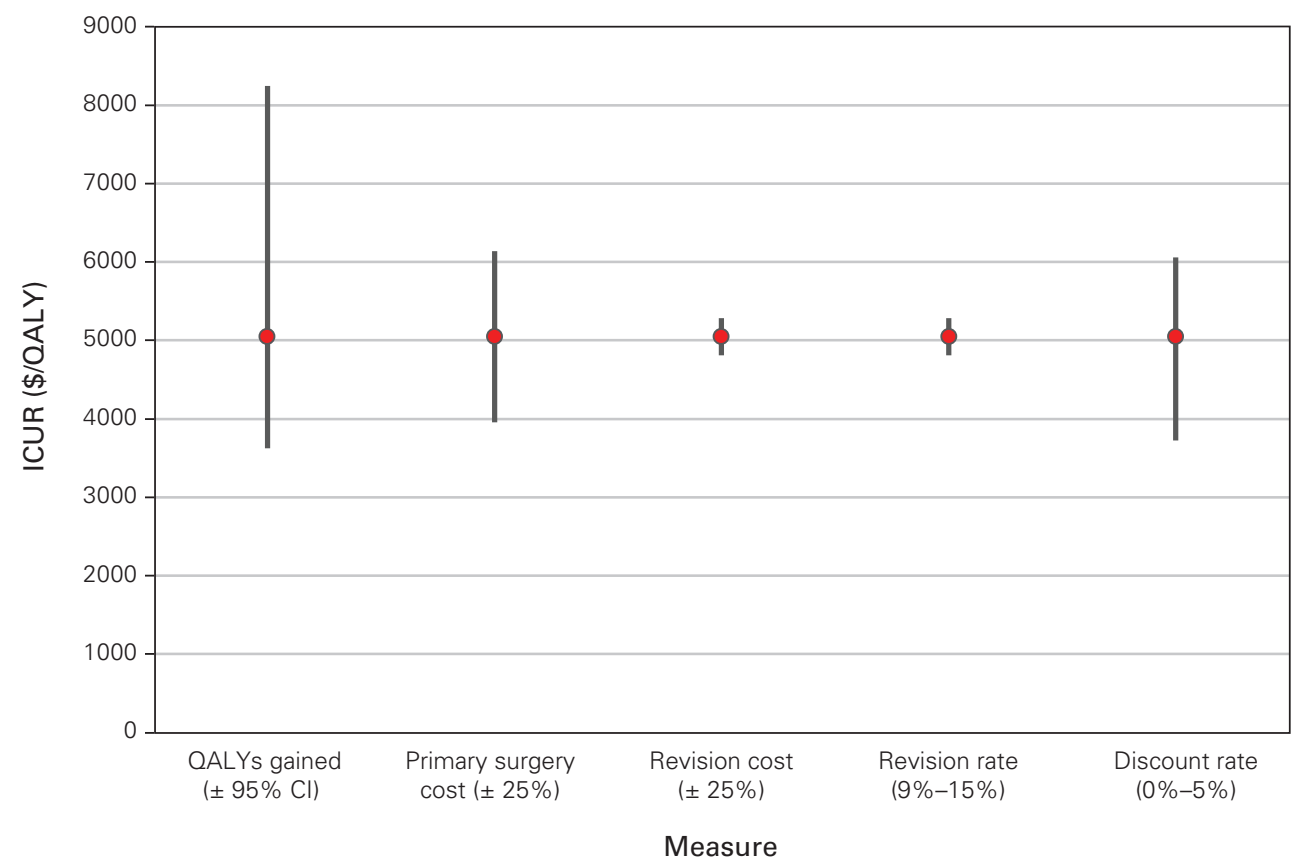

Fig. 3. Deterministic sensitivity analysis for the 35 patients with degenerative lumbar spondylolisthesis who underwent MIS decompression alone. $\mathrm{Cl}=$ confidence interval; ICUR = incremental cost-utility ratio; MIS = minimally invasive surgery; QALY = quality-adjusted life year. 


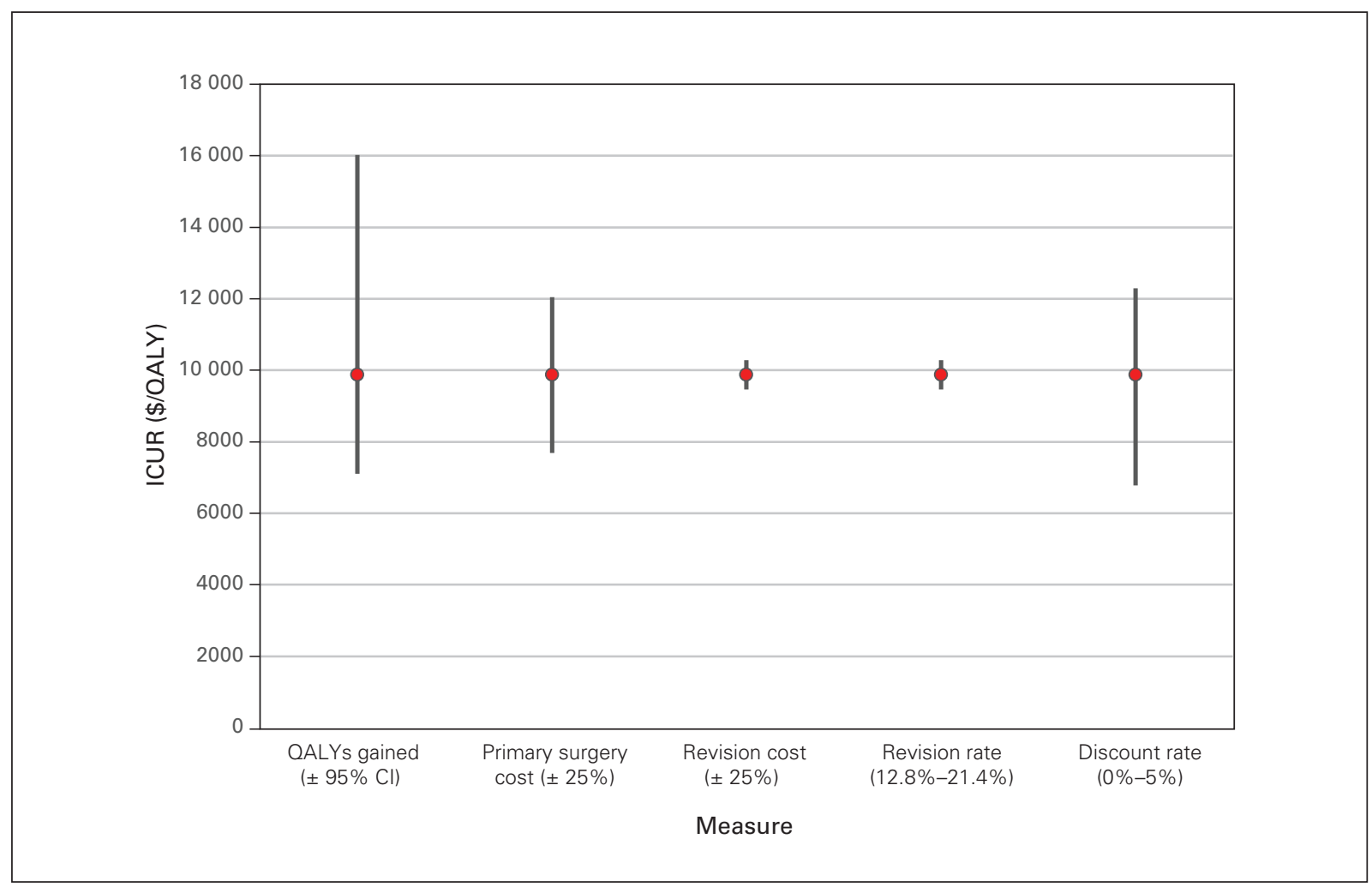

Fig. 4. Deterministic sensitivity analysis for the 31 patients with degenerative lumbar spondylolisthesis who underwent MIS decompression and fusion. $\mathrm{Cl}$ = confidence interval; ICUR = incremental cost-utility ratio; MIS = minimally invasive surgery; $\mathrm{QALY}=$ quality-adjusted life year.

findings are reproducible with random sampling across distributions of factors that influence the ICUR.

\section{Discussion}

This study compares the cost-utility of MIS for patients with DLS with that of a contemporaneous group of patients who underwent THA and TKA for hip and knee OA, respectively. We selected a homogeneous spine patient population and used identical data collection techniques with respect to costs and outcomes for all cohorts, allowing for a meaningful comparison of ICURs. After comparing all patients with DLS (who underwent decompression alone and decompression and fusion procedures) with patients who underwent TJR procedures, the ICURs were found to be comparable, with \$7946/QALY for DLS, \$7104/QALY for TKA and \$5098/QALY for THA. The certainty of these results was supported by the PSA, which yielded $95 \%$ CIs for ICURs generated for each cohort that varied only by approximately $\$ 200$ each. Additionally, the rank order of ICURs by cohort (THA < TKA < DLS) did not change with the PSA or with the presented best- and worst-case scenarios, providing internal validity to the results.

Subgroup analysis revealed a decreased ICUR for decompression alone (\$5045/QALY) compared with decompression and fusion procedures (\$9870/QALY). This reflects the decreased costs associated with decompression-alone procedures, notably reduced implant costs and costs related to LOS. Additionally, patients with DLS meeting the criteria for decompression and fusion procedures had lower utility scores at baseline and follow-up than matched patients undergoing TJR, suggesting that these patients have a more severe disease state than patients with hip or knee OA. This finding reinforces the fact that improved funding and access to surgery is needed for the DLS population. Furthermore, although fusion procedures were associated with increased costs compared with decompression-alone procedures, the lifetime QALYs gained were 2.276 for fusion and 1.658 for decompression-alone procedures.

The results of this study are congruent with those previously published ${ }^{8,21}$ and reinforce that the ICUR for the focal surgical management of a common degenerative spine condition, DLS, is comparable to that of total hip and knee arthroplasty for OA. Specifically, our methods are similar to those of Tso and colleagues, who reported a 2-year follow-up comparing ICURs for focal lumbar spine stenosis (with or without DLS) with ICURs for TKA and THA. ${ }^{21}$ They reported the relative rank order of the ICURs to be as follows: THA, followed by decompression, then decompression and fusion for LSS and 
lastly TKA, having the least favourable ICUR. The current study found that decompression and fusion for DLS had the least favourable ICUR, followed by TKA, THA and then decompression alone for DLS. This difference may be due to differences in the spine populations examined, as we included only patients with DLS, a subset of LSS. Furthermore, different surgical procedures were performed, specifically MIS procedures, which carry higher implant- and equipment-related costs but reduced hospital LOS costs compared with open surgery.

Another comparison to the study by Tso and colleagues that we made was in examining the absolute value for the ICURs, rather than looking at their relative ranking. When the ICURs reported by Tso and colleagues are inflated to 2016 Canadian dollars they are as follows: \$5971/QALY for THA, \$12652/QALY for TKA, \$2589/QALY for decompression alone for LSS and $\$ 8026$ /QALY for decompression and fusion for LSS. The increased ICURs reported for the spine cohorts in the current study appear to be due to increased costs of MIS procedures, as Tso and colleagues reported lower surgical costs but relatively similar utility gains at follow-up. The increased surgical costs are due to the fact that our study included indirect hospital (overhead) costs whereas the study reported by Tso and colleagues did not. Additionally, it can be seen that the costs of TKA and THA have both decreased over time, and this probably reflects the ongoing refinements to hip and knee arthroplasty postsurgical care pathways, which have resulted in decreased LOS, which is supported by our findings compared with those previously reported by Tso and colleagues. ${ }^{21}$ Tso and colleagues reported that the mean LOS for patients undergoing THA and TKA was 7.28 and 7.02 days, respectively. ${ }^{21}$ In contrast, in our study the mean LOS for patients undergoing TJR was 3.83 and 3.97 days, respectively. This reduction in LOS for patients undergoing TJR translated into significant cost savings, and by extension greatly improved ICURs.

The need for fusion-based procedures in certain patients with DLS remains controversial. ${ }^{35,36} \mathrm{Kim}$ and colleagues found that for patients with stable grade 1 DLS, decompression alone is significantly more cost effective than decompression and fusion procedures for patients with unstable or higher grade DLS. ${ }^{37}$ The results of our study echo these findings. Furthermore, when we examine the overall results of this study, in which $53 \%$ of patients underwent fusions, the ICURs were similar to those of patients undergoing TKA and THA for OA. Therefore, if a spine surgeon's practice consists of roughly a 50:50 mix of decompression alone and decompression and fusion procedures for DLS, the dollars spent would be expected to create approximately the same patient benefit as that generated by a hip or knee arthroplasty surgeon.

The strengths of this study include the selection of a homogeneous population of patients with DLS who underwent MIS procedures. Additionally, compared with previous studies by Rampersaud's group, to our knowledge this study is the first to include individual patient-level micro-costed data and associated hospital overhead costs and to examine the certainty of the study findings with a PSA.

\section{Limitations}

There are a number of limitations to this study. First, the DLS cohort represents a single-surgeon case series in a high-volume tertiary care centre. This raises questions related to the overall generalizability of the study, specifically whether or not similar outcomes could be achieved in the hands of the broader community of practice. However, a number of high-quality trials evaluating clinical outcomes in patients undergoing lumbar spine surgery have corroborated our results. The SPORT trial demonstrated statistically significant improvements in the SF-36 bodily pain score and physical component score and in ODI scores at 4-year follow-up. ${ }^{13}$ Similar results can be found in the MRC Spine Stabilization Trial, where statistically significant improvements in the ODI were noted at 2 year follow-up. ${ }^{38}$

Our study lacks follow-up beyond a 2-year time horizon, thereby shielding the results from longer term changes in utility scores or factors that could affect health care expenditures, such as the need for revision surgery. However, studies in the literature show durable results despite increased revision rates, based on an average follow-up of 11 years for patients with DLS undergoing open surgical treatment. ${ }^{8,34}$ Furthermore, a recent systematic review shows no significant outcome differences with respect to surgical and patient outcome for open versus MIS procedures for patients with DLS. ${ }^{14}$

By practical necessity our economic evaluation was done from the narrow perspective of the Ontario Ministry of Health, a single payer. Our analysis did not take into account, for example, the costs incurred by the patient or the costs associated with the surgeon's fee, which was not included in the hospital financial data. These factors must be taken into account when interpreting the results of our study.

This study failed to capture costs associated with decreased patient productivity or work absenteeism. Capturing and including these data may influence the ICURs for the procedures reported. In particular, the ICUR for the DLS cohort may be affected, as previous research on the cost-effectiveness of MIS versus open procedures for DLS demonstrated that the economic benefits of MIS were attributed to patients' early return to their regular activities, including their return to work. ${ }^{39}$ It therefore might be advantageous for future research in MIS spine surgery to adopt a societal perspective to capture further benefits associated MIS procedures, as we are still aiming to understand the potential economic benefits of MIS procedures in spine 
surgery. ${ }^{40}$ These data may also help to justify our reported increased surgical costs with MIS procedures compared with previous open procedures.

\section{ConcLusion}

The overall results of this study are consistent with previous reports in the literature that surgical management of DLS results in ICURs similar to those of TKA and THA. As the population ages and patient demand for surgery increases, it will be important that funding agencies acknowledge the benefit of spine surgery through adequate funding models to ensure that patients have access to cost-effective and evidence-based care.

Acknowledgements: The authors are grateful to Dr. Nizar Mahomed and Dr. Rod Davey for allowing them to use the Longitudinal Evaluation in the Arthritis Program (LEAP) registry for the matched hip and knee replacement cohorts.

Affiliations: From the Division of Orthopaedic Surgery, Department of Surgery, University of Toronto, Toronto, Ont. (Crawford, Rampersaud); the Institute of Health Policy, Management and Evaluation, University of Toronto, Toronto, Ont. (Crawford, Coyte); the Department of Orthopaedic Surgery, University of Arizona College of Medicine, Phoenix, Ariz. (Ravinksy); the Division of Orthopaedic Surgery, Toronto Western Hospital, University Health Network, Toronto, Ont. (Rampersaud); the Division of Neurosurgery, Toronto Western Hospital, University Health Network, Toronto, Ont. (Rampersaud); and the Spinal Program, Krembil Neuroscience Centre, Toronto Western Hospital, University Health Network, Toronto, Ont. (Rampersaud).

Competing interests: R. Rampersaud has received royalties from Medtronic and is the chief medical officer of Arthur Health. No other competing interests were declared.

Contributors: E. Crawford, P. Coyte and R. Rampersaud designed the study. E. Crawford, R. Ravinsky and R. Rampersaud acquired the data, which E. Crawford, R. Ravinsky and P. Coyte analyzed. E. Crawford and R. Ravinsky wrote the article, which R. Ravinksy and P. Coyte and R. Rampersaud critically revised. All authors gave final approval of the version to be published.

Content licence: This is an Open Access article distributed in accordance with the terms of the Creative Commons Attribution (CC BYNC-ND 4.0) licence, which permits use, distribution and reproduction in any medium, provided that the original publication is properly cited, the use is noncommercial (i.e., research or educational use), and no modifications or adaptations are made. See: https://creativecommons. org/licenses/by-nc-nd/4.0/

\section{References}

1. Kurtz S, Ong K, Lau E, et al. Projections of primary and revision hip and knee arthroplasty in the United States from 2005 to 2030. 7 Bone foint Surg Am 2007;89:780-85.

2. Deyo RA. Trends, major medical complications, and charges associated with surgery for lumbar spinal stenosis in older adults. $7 A M A$ 2010;303:1259.

3. Glassman SD, Carreon LY, Djurasovic M, et al. Lumbar fusion outcomes stratified by specific diagnostic indication. Spine 7 2009; 9:13-21.

4. Aono K, Kobayashi T, Jimbo S, et al. Radiographic analysis of newly developed degenerative spondylolisthesis in a mean twelve-year prospective study. Spine 2010;35:887-91.

5. Kalichman L, Kim DH, Li L, et al. Spondylolysis and spondylolisthesis: prevalence and association with low back pain in the adult community-based population. Spine 2009;34:199-205.
6. Jacobsen S, Sonne-Holm S, Rovsing H, et al. Degenerative lumbar spondylolisthesis: an epidemiological perspective: the Copenhagen Osteoarthritis Study. Spine (Phila. Pa. 1976) 2007;32:120-5.

7. Rampersaud YR, Lewis SJ, Davey JR, et al. Comparative outcomes and cost-utility after surgical treatment of focal lumbar spinal stenosis compared with osteoarthritis of the hip or knee - Part 1: longterm change in health-related quality of life. Spine 7 2014;14: 234-43.

8. Rampersaud YR, Tso P, Walker KR, et al. Comparative outcomes and cost-utility following surgical treatment of focal lumbar spinal stenosis compared with osteoarthritis of the hip or knee: Part 2 -estimated lifetime incremental cost-utility ratios. Spine 7 2014;14:244-54.

9. Ethgen $\mathrm{O}$, Bruyère $\mathrm{O}$, Richy $\mathrm{F}$, et al. Health-related quality of life in total hip and total knee arthroplasty. A qualitative and systematic review of the literature. 7 Bone Foint Surg Am 2004;86:963-74.

10. Malchau H, Herberts P, Eisler T, et al. The Swedish Total Hip Replacement Register. 7 Bone Foint Surg Am 2002;84(A Suppl 2):2-20.

11. Lavernia CJ, Guzman JF, Gachupin-Garcia A. Cost effectivness and quality of life in knee arthroplasty. Clin Orthop Relat Res 1997; (345):134-9.

12. Weinstein JN, Lurie JD, Tosteson TD, et al. Surgical compared with nonoperative treatment for lumbar degenerative spondylolisthesis. 7 Bone foint Surg Am 2009;91:1295-304.

13. Tosteson ANA, Tosteson TD, Lurie JD, et al. Comparative effectiveness evidence from the spine patient outcomes research trial. Spine (Pbila Pa 1976) 2011;36:2061-8.

14. Goldstein CL, Macwan K, Sundararajan K, et al. Comparative outcomes of minimally invasive surgery for posterior lumbar fusion: a systematic review. Clin Orthop Relat Res 2014;472:1727-37.

15. Park Y, Ha JW. Comparison of one-level posterior lumbar interbody fusion performed with a minimally invasive approach or a traditional open approach. Spine 2007;32:537-43.

16. Peng CWB, Yue WM, Poh SY, et al. Clinical and radiological outcomes of minimally invasive versus open transforaminal lumbar interbody fusion. Spine 2009;34:1385-9.

17. Rampersaud YR, Gray R, Lewis SJ, et al. Cost-utility analysis of posterior minimally invasive fusion compared with conventional open fusion for lumbar spondylolisthesis. SAS 7 2011;5:29-35.

18. Wang J, Zhou Y, Feng Z, et al. Comparison of one-level minimally invasive and open transforaminal lumbar interbody fusion in degenerative and isthmic spondylolisthesis grades 1 and 2. Eur Spine 7 2010;19:1780-4

19. Lee KH, Yue WM, Yeo W, et al. Clinical and radiological outcomes of open versus minimally invasive transforaminal lumbar interbody fusion. Eur Spine 7 2012;21:2265-70.

20. Ghahreman A, Ferch RD, Rao PJ, et al. Minimal access versus open posterior lumbar interbody fusion in the treatment of spondylolisthesis. Neurosurgery 2010;66:296-304.

21. Tso P, Rampersaud YR. Comparison of lifetime incremental cost: utility ratios of surgery relative to failed medical spine osteoarthritis modelled using 2-year postsurgical values. Can 7 Surg 2012;55:181-90.

22. Husereau D, Drummond M, Petrou S, et al. Consolidated Health Economic Evaluation Reporting Standards (CHEERS) statement. Eur 7 Health Econ 2013;14:367-72.

23. Statistics Canada. Complete life tables 2009-2011. Ottawa: Statistics Canada; 2011. Available: https://www150.statcan.gc.ca/n1/pub/ 84-537-x/84-537-x2020001-eng.htm (accessed 2017 Jan. 19).

24. Drummond MF, Sculpher MJ, Torrance GW, et al. Methods for the economic evaluation of health care programmes. Oxford (UK): Oxford University Press; 2005.

25. Brazier J, Roberts J, Deverill M. The estimation of a preference-based measure of health from the SF-36. F Health Econ 2002;21:271-92.

26. Bank of Canada. Inflation calculator. 2017. Available: https://www. bankofcanada.ca/rates/related/inflation-calculator/ (accessed 2017 Jan. 19). 
27. Mahomed NN, Davis AM, Hawker G, et al. Inpatient compared with home-based rehabilitation following primary unilateral total hip or knee replacement: a randomized controlled trial. 7 Bone foint Surg Am 2008;90:1673-80.

28. Health Quality Ontario, Ministry of Health and Long-Term Care. Quality-based procedures clinical handbook for primary hip and knee replacement. Toronto: Health Quality Ontario; 2013.

29. GTA Rehab Network. MSK Flow task group initiative: primary, elective, unilateral total joint replacement. Toronto (ON): GTA Rehab Network; 2011.

30. Ministry of Health and Long-term Care. Schedule of benefits. Toronto $(\mathrm{ON})$ : Ministry of Health and Long-term Care; 2015.

31. Ministry of Health and Long-term Care. Schedule of facility fees. Toronto (ON): Ministry of Health and Long-term Care; 2015. Available: (accessed 2017 Jan. 19).

32. Ontario Ministry of Health and Long-Term Care. Ontario Case Costing Initiative. 2011. Available: https://hsimi.on.ca/hdbportal/ (accessed 2017 Jan. 19).

33. Labek G, Thaler $M$, Janda $W$, et al. Revision rates after total joint replacement. F Bone Foint Surg Br 2011;93:293-7.

34. Martin BI, Mirza SK, Comstock BA, et al. Reoperation rates following lumbar spine surgery and the influence of spinal fusion procedures. Spine 2007;32:382-7.

35. Wilson-MacDonald J, Fairbank J, Frost H, et al. The MRC Spine Stabilization Trial. Spine (Phila Pa 1976) 2008;33:2334-40.

36. Parker SL, Mendenhall SK, Shau DN, et al. Minimally invasive versus open transforaminal lumbar interbody fusion for degenerative spondylolisthesis: comparative effectiveness and cost-utility analysis. World Neurosurg 2014;82:230-8.

37. Phillips FM, Cheng I, Rampersaud YR, et al. Breaking through the 'glass ceiling' of minimally invasive spine surgery. Spine (Phila Pa 1976) 2016;41(Suppl 8):S39-43.

38. Försth P, Ólafsson G, Carlsson T, et al. A randomized, controlled trial of fusion surgery for lumbar spinal stenosis. $N$ Engl 7 Med 2016;374:1413-23.

39. Ghogawala Z, Dziura J, Butler WE, et al. Laminectomy plus fusion versus laminectomy alone for lumbar spondylolisthesis. N Engl $7 \mathrm{Med}$ 2016;374:1424-34.

40. Kim S, Mortaz Hedjri S, Coyte PC, et al. Cost-utility of lumbar decompression with or without fusion for patients with symptomatic degenerative lumbar spondylolisthesis. Spine 7 2012;12:44-54. 